due to his peculiar method of locomotion. Jater he developed delusions of suspicion, became somewhat unmanageable, and was finally brought to the almshouse.

Chicago, Illinois.

\section{A CAUTION AGAINST THE USE OF KEROSENE IN} THE TREATMENT OF PEDICULOSIS CAPITIS.

By Maurice Edwn PaUl, M.D. Brux., M.R.C.S. ENG., L.R C.P. LOND.

ONE of the most convenient methods of treating pediculosis capitis is by rubbing the scalp and hair with kerosene. It instantly destroys the lice, it loosens the nits, and it soothes the cutaneous irritation. The recent death from burns consequent on the spontaneous ignition of hair that was being rubbed after the application of a hair-wash consisting principally of kerosene makes it necessary, however, to reject the use of kerosene as a parasilicide lotion to the hair. It appeared from the inquest in the above-mentioned case that the ignition of the hair was unquestionably not brought about by any naked light; and Lord Kelvin suggested (in a letter to the Times) that an explosive mixture of air and kerosene vapour having formed in the interstices of the hair this mixture was then ignited by an electric spark formed by friction of the bair. It is evident that no amount of care could guard against the repetition of this accident when kerosene was being applied to the hair.

Nagasaki, Japan.

\section{A Altirror $^{2}$}

\section{$O F$}

\section{HOSPITAL PRACTICE, BRITISH AND FOREIGN.}

Nulla autem est alia pro certo noscendi via, nisi quamplurimas et morborum et dissectionum historias, tum aliorum tum proprias colloctas habere, et inter se comparare.-MOBGsGNI De Sed. et Caus. Horb., lib. iv. Procmium.

\section{LONDON TEMPERANCE HOSPITAL.}

A CASE OF RUPTURED PYOSALPINY CLOSELY SIMULATING PERFORATION OF THE APPENDIX; NECROPSY.

(Under the care of Dr. SolTAU FENTICK.)

THE difficulties of diagnosis in cases of localised peritonitis are very great, not with regard to the fact of peritonitis but with regard to the cause, and in the following case the pain situated in the hypogastric and right iliac regions was very suggestive of perforation of the vermiform appendix, but the pelvic signs pointed strongly to a pelvic origin of the disease. From the post-mortem examination it was obvious that there had been an attempt to localise the peritonitis, but this had failed and a general infection of the peritoneum had resulted. The commencement of the pyosalpinz probably occurred at the parturition twenty-one months before admission to the bospital.

A woman, aged thirty-nine years, was admitted into the London Temperance Hospital on Oct. 6th suffering from abdominal pain. The patient stated that she had been in good health until her second confinement twenty-one months previously, after which she was laid up for five weeks with "inflammation of the bowels." Since her recovery from that complaint the catamenia had appeared every fortnight, but she had rever suffered from constipation, abdominal pain, or dyspepsia. Ten days before admission, while apparently in perfect health, she was seized with vomiting, which continued throughout the night and part of the nex day. Under the impression that she was bilious she took a couple of pills which acted freely on the bowels. In the evening, however, she was suddenly attacked by severe pain in the abdomen. For the first few hours the umbilical and right iliac regions were the chief seat of the suffering, but subsequently the pain became diffused over the whole abdomen, and at the same time she felt feverish and thirsty. When admitted to the hospital the patient had the appearance of being extremely ill. The face was flushed and the tongue was furred; the pulse-rate was 112 and the te roperature was $102.8^{\circ} \mathrm{F}$. A liquid and offensive motion was paszed suon afterwards, and several ounces of yellow bile were vomited. The tongue was moderately furred but moist, and the urine, which was roided without pain, contaiced a trace both of sugar and of albumin. On examination the lower half of the abdomen was found to be slightly distenced and somewhat tender on pressure. The pain was chiefly refierred to the hypogastric and right iliac regions, but neither trmour nor sense of resistance could be detected, while the percussion note was uniformly tympanitic. On vaginal examination the uterus was found to be xather low in the pelvis, and firmly fixed in the median line as though set in plasternotParis. The finger inserted into the rectum encountered the same sense of resistance when pressure was mace in a lateral direction. but no bulging or tumour could be felt, nor did the examination cause the patient undue pain. The other organs of the body were apparently normal. In vieg of these physical signs pelvic peritonitis was diagnosed, and the patient was ordered small doses of opium, while the abdomen was frequently fomented. On the following morring (ths 7th) she appeared to be considerably better. The teriperature bad fallen to a point slightly over 101, the pu'se and respiration had diminished in frequency, and little compiain was male of abdominal pain. On the 8 th the temperature had fallen another degree, the pain was less troublesome. while in response to an enerna a considerable quantity of fæcal material had been evacuated. The abdomen was still somewhat distended inferior]y, and pain was experifnced oa deep palpation over the region of the crcum. There was no dulness on percussion over this part, nor could anj localised fulness or tumour be detected by the finger in the rectum. After remaining in abont the sawe stale for two days the patient became markedly worse. The vomiting recurred and an access of pain in the lower part of the abdomen was complained of, The temperature rose to $103.4^{\circ}$ and the pulse varied between 112 and 120 . The abdomen was now found to be uniformly distended, axid pressure over the right iliac region gave rise to pain and nansea. Comparative duIness on percussion was detected over the position of the crecum, but there was neither swelling nor sense of resistance there or in the loin. Taking into consideration the gravity of the generat symptoms, with the increased distension of the abdo. men and the development of comparative dulness on percussion over the cæcum, it seemed probable that there was a collection of pus in the right side of: the pelvis which was making its way behind the crocure and coming forwards between that orgen and the addominat. parietes like an ordinary perityphlitic abscess. A consullation was consequently arranged with Dr. W. J. Collins, who agreed to perform an exploratory operation early the jollowing morning. Unfortunately, however, a few hours later the patient was attacked with collapse and rapinly sucrumbed.

Necropsy. - The small intesines were foutd to be gitatiy congested and spotted with flakes of lympb. On lifeing the integuments covering the right iliac fossa and orawing the crecum inwards a quantity of pus made its escass from beneath the bowel. On further examination a cavily contain ing about five ounces of pus was found to occupg the uppex part of the right half of the pelfis, the intersal wall nt the sac being formed by the aterus and numerous old achesionat existing between that organ and the other pelvic viscera. while its upper boundary consisted of several andherent coils of small gut. Hanging in the middle of the abrcess cavity was a well developed and perfectly healthy vermifcrm appendix. In close proximity to it was a pyosalpinx of the right Fallopian tube resembling a small walnut in size and shape, the rupture of which was responsible for the pelsi: inflammation.

\section{LIVERPOOL NORTEERN HOSPITAL}

A CASE OF ACUTE GENELAL SUPPURATIVE PERITONJTTR IREATED BY LAPAROTOMY; RECOVERY.

(Under the care of Mr. CHAUNCY PUzer.)

IN The Lancet of Oct. 9 ih, 1897, p. 916, we published a case of acute general peritonitis under the care of $\mathrm{Mr}$. Letonaxd Gamgee in which recovery followed the washing ot of the abdominal cavity, and a fair number of cases are now on record in which this treatment las proved su cessful; bot the mortality mus always remain higb for many of the 